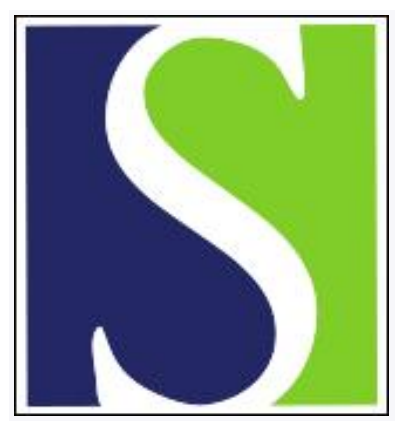

Scand J Work Environ Health 2002;28(4):249-255

https://doi.org/10.5271/sjweh.672

Issue date: Aug 2002

\title{
Sleep apnea and occupational exposure to solvents
}

by Heiskel H, Gunzenhäuser D, Seidler A, Volk S, Pflug B, Kauppinen T, Elsner $\mathrm{G}$

Affiliation: Institute of Occupational Medicine, Johann Wolfgang Goethe-University, Clinic, Frankfurt/Main, Germany. G.Elsner@em.uni-frankfurt.de

Key terms: case-control study; case-referent study; job-exposure matrix; occupational exposure; sleep apnea; solvent

This article in PubMed: www.ncbi.nlm.nih.gov/pubmed/12199426

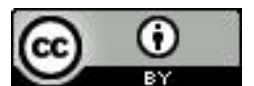




\title{
Sleep apnea and occupational exposure to solvents
}

\author{
by Harald Heiskel, MD, ${ }^{1}$ Ditz Gunzenhäuser, MD, ${ }^{1}$ Andreas Seidler, MD, ${ }^{1}$ Stephan Volk, MD, ${ }^{2}$ Burkhard \\ Pflug, MD, ${ }^{3}$ Timo Kauppinen, PhD, ${ }^{4}$ Gine Elsner, MD ${ }^{1}$
}

\begin{abstract}
Heiskel H, Gunzenhäuser D, Seidler A, Volk S, Pflug B, Kauppinen T, Elsner G. Sleep apnea and occupational exposure to solvents. Scand J Work Environ Health 2002;28(4):249-255.
\end{abstract}

\begin{abstract}
Objectives The possible effects of exposure to neurotoxic substances such as gasoline, diesel fuel, paint, varnish, and solvents on the pathogenesis of obstructive sleep apnea were examined.

Methods Four hundred and forty-three persons with incident obstructive sleep apnea were recruited within the framework of a case-referent study. A reference population $(\mathrm{N}=397)$ was included as the first reference group. In addition 106 patients whose sleep laboratory findings confirmed that they were not suffering from obstructive sleep apnea were then included as a second reference group. Data were gathered with a questionnaire which had to be filled out by the persons with obstructive sleep apnea (cases) and the referents themselves. In the assessment of occupational exposure the questionnaires were filled out by the subjects themselves, and a job-exposure matrix was also used. Data were analyzed using logistic regression to control for age, region, body mass index, cigarette smoking, and alcohol consumption.

Results None of the exposures were statistically significantly associated with obstructive sleep apnea. There was no correlation with occupation. Only current activities in service occupations revealed an increased odds ratio, 1.6 (95\% confidence interval 1.1-2.4).

Conclusions No suggestion was found of an association between exposure to solvents and obstructive sleep apnea.
\end{abstract}

Key terms sleep apnea, case-control study, case-referent study, job-exposure matrix, occupational exposure to solvents.

The obstructive sleep apnea syndrome is a sleep-related respiratory disorder in which an obstructive interruption of respiration lasting 10 seconds or more occurs more than 10 times each hour during sleep (1). The estimated prevalence of obstructive sleep apnea among men aged 30 to 60 years is roughly $4 \%$ (2).

During the day, patients suffer from concentration gaps, sleepiness, and a lack of motivation. Some observe morning headaches, complain of night sweating, suffer from depressive moodiness, and sometimes also impotence. Arterial hypertonia $(3,4)$, pulmonal arterial hypertonia (5), life-threatening cardiac rhythm disorders (6), myocardiac arrests (7), and cardiac insufficiency (8) have been observed as a result of obstructive sleep ap- nea. In addition, recurring, nighttime hypoxia leads to transitory ischemic attacks, even apoplexy (9). The daytime sleepiness caused by the sleeping disorders at night leads to a considerably increased risk of accidents in traffic (10). These consequences mean that apnea patients are 1.5-3 times more likely to die than other persons of the same age $(11,12)$.

Several characteristics are associated with obstructive sleep apnea. Men are affected more frequently than women (13). Obesity and distribution of fat mainly along the trunk and the neck in particular predict the development of obstructive sleep apnea (13). Alcohol consumption and medicine can also contribute to respiratory regulation disorders at night (14).

1 Institute of Occupational Medicine, Johann Wolfgang Goethe-University Clinic, Frankfurt/Main, Germany.

2 Hofheim Specialist Clinic, Hofheim am Taunus, Germany.

3 Clinic for Psychiatry and Psychotherapy II, Johann Wolfgang Goethe-University Clinic, Frankfurt/Main, Germany.

4 Finnish Institute of Occupational Health, Helsinki, Finland.

Reprint requests to: Prof Dr Gine Elsner, Institute of Occupational Medicine, Johann Wolfgang Goethe-University, Clinic, Frankfurt/Main, Germany. [E-mail: G.Elsner@em.uni-frankfurt.de] 


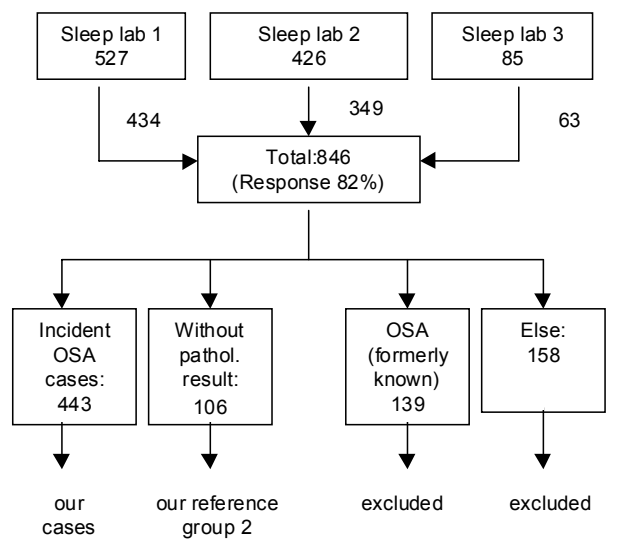

Figure 1. Recruitment of the cases and reference group 2. (OSA=0bstructive sleep apnea, lab=laboratory)

After the publication of some case studies $(15,16)$, there have been claims that substances in the work environment may cause sleep apnea. In a group of 66 men exposed to solvents, a Swedish study found 13 persons with signs associated with obstructive sleep apnea (17). In comparison to the prevalence of obstructive sleep apnea among Swedish men of the same age, the odds ratio (OR) was 14.1 .

A Norwegian study revealed an increased prevalence of obstructive sleep apnea among a group of 51 persons with solvent exposure in comparison with 18 unexposed referents (18). A prevalence of 30\% for obstructive sleep apnea among exposed persons, compared with $6 \%$ for unexposed persons, was determined. The apnea indices dropped within 2 weeks after the end of the exposure. After the resumption of the exposed occupation, an increase in the apnea indices was registered after 1 year.

Another study examined the solvent exposure of 288 patients with obstructive sleep apnea in comparison with 296 population referents (19). The odds ratios, which were adjusted for body mass index, age, smoking, alcohol consumption, beta-blockers, benzodiazepine, high blood pressure, and heart diseases, revealed that the estimated risk was almost doubled [OR 1.94, 90\% confidence interval (90\% CI) 1.1-3.4] if the patient was presumably exposed to high concentrations of solvents daily.

A German study interviewed 184 staff members of a company producing color film components with regard to symptoms associated with sleep apnea syndrome (20). There was no excess of sleep apnea among the solvent-exposed workers. It was not possible to determine any connection between the complaint symptoms and a biomarker for solvent exposure (acetone secretion in urine).

We carried out a case-referent study in order to examine the influence of solvents on sleep apnea.

\section{Subjects and methods}

\section{Subjects}

To identify incident cases of obstructive sleep apnea, we asked all male patients who were referred to one of the three (participating) sleep laboratories in Frankfurt am Main by their general practitioners to clarify dyssomnia (sleeping disorders) during the recruitment period of May 1997 until June 1998, before the diagnosis, whether they would be willing to take part in the study (figure 1). Altogether 846 of the 1038 persons who were asked, filled out the questionnaire, corresponding with a response rate of $82 \%$. After polysomnography (21), $52.4 \%(\mathrm{~N}=443)$ of the subjects were diagnosed with obstructive sleep apnea. This group was our case group (table 1). No pathological findings were determined for 106 persons (12.5\%). This group was our second reference group (table 1). This reference group had the advantage that it was the most similar to the case group, the difference being that obstructive sleep apnea could be excluded in these cases. Any differences from the case group could therefore not be explained in terms of different access to sleep laboratories, but instead should be viewed causally. In addition to the small group size, its disadvantage was that its nonspecific symptoms may have been caused by the same factors as the sleep apnea. These factors may be, for example, chronic intoxication or encephalopathy caused by solvents or other neurotoxic substances. If this is the case, the possible connection may be hidden.

Altogether 139 persons had already suffered from diagnosed sleep apnea for a long time. Sometimes their illness had begun many years ago and could not be established with certainty; some persons had already been treated often in sleep laboratories. We eliminated these 139 patients from further examination to collect data only from new cases because the exposures were only calculated from the beginning of the illness. Altogether 158 persons with other diagnoses (narcolepsy, hyperventilation, etc) were also excluded.

A population-based reference group was also included (table 1). This group had the advantage that it was, in the widest sense, a representative group of the examination region. In addition to the assumed epidemiologic differences in the access to sleep laboratories (and not with regard to etiologically relevant characteristics), its disadvantage was that persons suffering from obstructive sleep apnea could also be expected in this group. However, as only a very small number of them, if at all, could be explained as a result of exposure to solvents, this aspect was unlikely to lead to any relevant distortion. To recruit the population-based reference group from the same region as the cases, we included a random sample of the population from Frankfurt am Main 
Table 1. Descriptive characteristics for the cases of obstructive sleep apnea and the two reference groups. (BMI=body mass index)

\begin{tabular}{|c|c|c|c|c|c|c|}
\hline \multirow[t]{2}{*}{ Characteristic } & \multicolumn{2}{|c|}{ Cases $(\mathrm{N}=443)$} & \multicolumn{2}{|c|}{ Population-based reference group ( $N=397$ ) } & \multicolumn{2}{|c|}{ Sleep laboratory reference group $(N=106)$} \\
\hline & $\mathrm{N}$ & $\%$ & N & $\%$ & N & $\%$ \\
\hline \multicolumn{7}{|l|}{ Age $^{a}$} \\
\hline 20-29 years & 10 & 2.3 & 7 & 1.8 & 8 & 7.5 \\
\hline 30-39 years & 30 & 6.8 & 56 & 17.1 & 15 & 14.2 \\
\hline 40-49 years & 77 & 17.4 & 77 & 19.4 & 21 & 19.8 \\
\hline $50-59$ years & 171 & 38.6 & 93 & 23.4 & 39 & 36.8 \\
\hline $60-69$ years & 113 & 25.5 & 122 & 30.7 & 18 & 17.0 \\
\hline $70-79$ years & 29 & 6.5 & 41 & 10.3 & 4 & 3.8 \\
\hline $80-89$ years & 1 & 0.2 & - & - & - & - \\
\hline Unknown & 12 & 2.7 & 1 & 0.3 & 1 & 0.9 \\
\hline \multicolumn{7}{|l|}{$\mathrm{BMI} \mathrm{b}^{\mathrm{b}}$} \\
\hline$\leq 25.50 \mathrm{~kg} / \mathrm{m}^{2}$ & 53 & 12.0 & 178 & 44.8 & 29 & 27.4 \\
\hline $25.51-27.94 \mathrm{~kg} / \mathrm{m}^{2}$ & 93 & 21.0 & 117 & 29.5 & 30 & 28.3 \\
\hline $27.95-31.48 \mathrm{~kg} / \mathrm{m}^{2}$ & 120 & 27.1 & 74 & 18.6 & 24 & 22.6 \\
\hline$>31.48$ kg/m² & 148 & 33.4 & 25 & 6.3 & 16 & 15.1 \\
\hline Unknown & 29 & 6.5 & 3 & 0.8 & 7 & 6.6 \\
\hline \multicolumn{7}{|l|}{ Alcohol intake } \\
\hline$\leq 7$ glasses/week & 232 & 52.4 & 228 & 57.4 & 71 & 67.0 \\
\hline 8-13 glasses/week & 127 & 28.7 & 109 & 27.5 & 21 & 19.8 \\
\hline 14-21 glasses/week & 36 & 8.1 & 44 & 11.1 & 10 & 9.4 \\
\hline >21 glasses/week & 22 & 5.0 & 16 & 4.0 & 3 & 2.8 \\
\hline Unknown & 26 & 5.9 & - & - & 1 & 0.9 \\
\hline \multicolumn{7}{|l|}{ Smoking } \\
\hline Nonsmoker & 104 & 23.5 & 127 & 32.0 & 34 & 32.1 \\
\hline (Ex)smoker & 321 & 72.5 & 270 & 68.0 & 71 & 67.0 \\
\hline Unknown & 18 & 4.1 & - & - & 1 & 0.9 \\
\hline
\end{tabular}

a Mean 54.8 (SD 10.5) years for the cases, 54.2 (SD 12.6) years for the population-based reference group, 49.8 (SD12.3) years for the sleep laboratory reference group.

${ }^{b}$ Mean 30.6 (5.5) for the cases, 26.2 (4.2) for the population-based regerence group, and 27.9 (4.8) for the sleep laboratory reference group.

and the surrounding regions as the first reference group. For the Frankfurt part of the reference group, a representative random sample of $1 \%$ was taken of the men aged 30 to 80 years in Frankfurt am Main. Fifteen percent of the 2540 persons were chosen at random and selected in age quotas. Altogether 349 of these 381 persons had the opportunity to take part in the study. A total of 196 of them responded, corresponding with a response rate of $56 \%$ (figure 2).

Random samples outside of Frankfurt were not available. Therefore, the population referents were recruited using "random digit dialing" in order to compensate for the expected distribution of residences. A total of 201 additional persons were recruited for the study using this method. The response rate for this method was $63 \%$. A total of 397 persons were therefore recruited for the reference group. The average response rate for all the subjects in this reference group was 59\%.

\section{Exposure assessment}

All the persons in the case group and the two reference groups were asked to fill out a questionnaire regarding all job titles with a duration of 1 year or longer (accord-

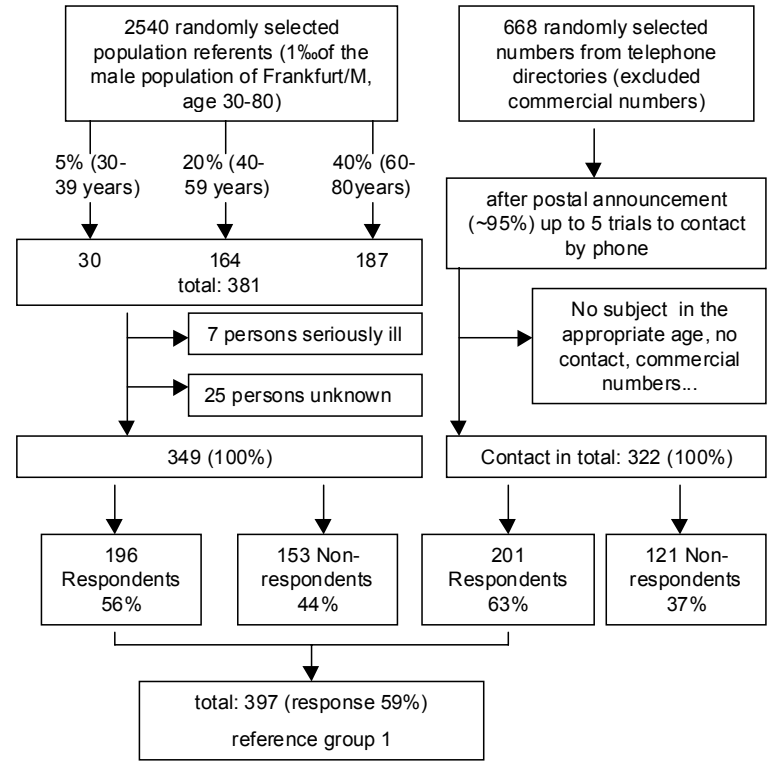

Figure 2. Recruitment of reference group 1.

ing to the Federal Statistical Code 1992). Categorized on three levels of duration (none, $<10$ years, $\geq 10$ years), they were included in the logistical regression model. 
Odds ratios were then calculated and adjusted for body mass index, age, alcohol consumption, smoking, and region of origin.

The subjects were asked to state whether they were exposed to the four selected substances (gasoline, diesel fuel, solvents, paints) "daily", "weekly", "monthly", or "never". The subjects were also asked how many years they had been exposed to these substances. The details were summarized, whereby "low exposure" was assumed if the test subject selected "monthly", regardless of the duration, or "weekly" if the duration of exposure was less than 10 years. "Medium exposure" was assumed if the test person stated "weekly" exposure for $\geq 10$ years or "daily" exposure for $<10$ years in the rough data. "High exposure" was only assumed if the test subject stated "daily" exposure for $\geq 10$ years. The exposure-related data were included in the calculations separately. Adjusted odds ratios were calculated. The level of significance and confidence intervals (CI) were calculated using the statistics program SPSS (Statistical Package for the Social Sciences, version 9.0).

As the results of previous studies gave grounds for the assumption that the apnea-inducing effects of solvents particularly take place in the event of acute exposure and that the symptoms lessen within 2 weeks of the cessation of exposure (18), we differentiated between current and former exposure by considering whether the categorized exposure frequency had been maintained until the year of the interview or diagnosis. In addition we reviewed the influence of the current occupation by including this variable in the model of the logistic regression, and adjusting it for the mentioned confounders.

We further used the occupational description to estimate the exposure to solvents using a job-exposure matrix (22). This matrix was constructed by industrial hygienists of the Finnish Institute of Occupational Health. It contains occupation-specific estimates of probability (as the percentage) and level (parts per million) of exposure for four different categories of solvents. The subjects were classified as exposed if the probability of exposure according to the job-exposure matrix exceeded $50 \%$. The median of the accumulated exposure level among the exposed persons was 197 ppm-years. If the exposure was lower than this cut point, the exposure was categorized as being "low", and, if it was above the said cut-point, it was considered "high". It was then included in the logistic regression model as a categorized variable.

\section{Confounders}

In comparison with the second reference group (ie, the persons whose sleeping laboratory findings excluded any possibility of obstructive sleep apnea = sleeping laboratory reference group), the cases were an average of
5 years older, or 54.8 years. The mean age of the population-based reference group was 54.2 years. A comparison of the body mass index (BMI) showed a higher BMI for the case group (mean $30.6 \mathrm{~kg} / \mathrm{m}^{2}$ ) than for the population reference group (mean $26.2 \mathrm{~kg} / \mathrm{m}^{2}$ ). The sleeping laboratory reference group differed only slightly (mean $27.9 \mathrm{~kg} / \mathrm{m}^{2}$ ). There is a lower proportion of persons in the case group who drank little or no alcohol $(52.4 \%)$ than in the population reference group (57.4\%) and the sleeping laboratory reference group (67\%). Nonsmokers were also less frequent in the case group $(23.5 \%)$ than in the population reference group (32\%) or sleeping laboratory reference group $(32.1 \%)$.

\section{Results}

\section{Exposure}

None of the exposures inquired about (gasoline, diesel fuel, solvents, paints) had a statistically significant association with obstructive sleep apnea (table 2). This finding applied to both reference groups. A comparison with the sleeping laboratory reference group revealed odds ratios between 0.2 and 1.4 , also without any relationship between dose and response.

The odds ratios for "low", "medium", and "high" exposure to solvents were between 0.8 and 1.2 if the population referents were used in the comparison. The odds ratios in a comparison with the sleeping laboratory referents were between 0.8 and 1.0.

There were no statistically significant odds ratios for current exposure (ie, exposure up to the date of the interview, data not shown). The odds ratios for current solvent exposure in comparison with that of the population referents were 0.6 (95\% CI 0.3-1.2) for "monthly" exposure, 1.1 (95\% CI 0.4-3.3) for "weekly" exposure, and 0.4 (95\% CI 0.2-1.1) for "daily" exposure. The odds ratios in the comparison with the sleeping laboratory reference group were also nonsignificant (OR 1.7, 95\% CI 0.5-6.4; OR 0.4, 95\% CI 0.1-1.1; and OR 3.0, 95\% CI 0.4-26.3, for the relevant exposure categories).

\section{Occupation}

There were no significant elevated risks for cumulated activity in certain occupations (data not shown). In the case group, $56.7 \%$ were still working as opposed to $58.4 \%$ in the population reference group and $63.2 \%$ in the sleeping laboratory reference group (data not shown). When adjusted for age, region, BMI, alcohol consumption, and smoking, the current occupation in 
Table 2. Exposure of the cases of obstructive sleep apnea and the two reference groups to different substances. (OR $=0 d d s$ ratio, $95 \% \mathrm{Cl}=95 \%$ confidence interval)

\begin{tabular}{|c|c|c|c|c|c|c|c|c|c|c|}
\hline \multirow[t]{2}{*}{ Exposure } & \multicolumn{2}{|c|}{ Cases } & \multicolumn{4}{|c|}{ Population-based reference group } & \multicolumn{4}{|c|}{ Sleep laboratory reference group } \\
\hline & $\mathrm{N}$ & $\%$ & N & $\%$ & $\mathrm{OR}^{\mathrm{a}}$ & $95 \% \mathrm{Cl}$ & $\mathrm{N}$ & $\%$ & $\mathrm{OR}^{\mathrm{a}}$ & $95 \% \mathrm{Cl}$ \\
\hline \multicolumn{11}{|l|}{ Gasoline } \\
\hline None & 306 & 69.1 & 276 & 69.5 & 1.0 & & 62 & 58.5 & 1.0 & \\
\hline Low & 57 & 12.9 & 46 & 11.6 & 1.1 & $0.6-1.8$ & 15 & 14.2 & 0.7 & $0.4-1.4$ \\
\hline Medium & 53 & 12.0 & 44 & 11.1 & 0.9 & $0.6-1.6$ & 12 & 11.3 & 0.9 & $0.4-1.9$ \\
\hline High & 27 & 6.1 & 31 & 7.8 & 0.6 & $0.3-1.2$ & 17 & 16.0 & 0.2 & $0.1-0.5$ \\
\hline \multicolumn{11}{|l|}{ Diesel fuel } \\
\hline None & 329 & 74.3 & 316 & 79.6 & 1.0 & & 77 & 72.6 & 1.0 & . \\
\hline Low & 38 & 8.6 & 35 & 8.8 & 0.8 & $0.4-1.5$ & 9 & 8.5 & 1.0 & $0.4-2.5$ \\
\hline Medium & 47 & 10.6 & 28 & 7.1 & 1.2 & $0.7-2.2$ & 8 & 7.5 & 1.4 & $0.6-3.3$ \\
\hline High & 29 & 6.5 & 18 & 4.5 & 1.0 & $0.5-2.2$ & 12 & 11.3 & 0.5 & $0.2-1.0$ \\
\hline \multicolumn{11}{|l|}{ Paints } \\
\hline None & 313 & 70.7 & 281 & 70.8 & 1.0 & & 67 & 63.2 & 1.0 & . \\
\hline Low & 64 & 14.4 & 67 & 16.9 & 0.8 & $0.5-1.2$ & 21 & 19.8 & 0.6 & $0.3-1.1$ \\
\hline Medium & 43 & 9.7 & 32 & 8.1 & 1.0 & $0.5-1.7$ & 11 & 10.4 & 0.9 & $0.4-2.0$ \\
\hline High & 23 & 5.2 & 17 & 4.3 & 1.0 & $0.4-2.2$ & 7 & 6.6 & 0.5 & $0.2-1.5$ \\
\hline \multicolumn{11}{|l|}{ Solvents } \\
\hline None & 285 & 64.3 & 276 & 69.5 & 1.0 & & 65 & 61.3 & 1.0 & . \\
\hline Low & 78 & 17.6 & 53 & 13.4 & 1.2 & $0.8-1.9$ & 18 & 17.0 & 1.0 & $0.5-1.9$ \\
\hline Medium & 48 & 10.8 & 40 & 10.1 & 1.1 & $0.6-1.9$ & 14 & 13.2 & 0.8 & $0.4-1.6$ \\
\hline High & 32 & 7.2 & 28 & 7.1 & 0.8 & $0.4-1.6$ & 9 & 8.5 & 0.8 & $0.3-1.8$ \\
\hline
\end{tabular}

a Odds ratio adjusted for age, body mass index, smoking, alcohol intake, and region.

Table 3. Odds ratios (OR) for obstructive sleep apnea by cumulative exposure to solvents as assessed with a job-exposure matrix. (95\% $\mathrm{Cl}=95 \%$ confidence interval)

\begin{tabular}{|c|c|c|c|c|c|c|c|c|c|c|}
\hline \multirow[t]{2}{*}{ Exposure } & \multicolumn{2}{|c|}{ Cases } & \multicolumn{4}{|c|}{ Population-based reference group } & \multicolumn{4}{|c|}{ Sleep laboratory reference group } \\
\hline & N & $\%$ & N & $\%$ & $O R^{a}$ & $95 \% \mathrm{Cl}$ & $N$ & $\%$ & $O R^{a}$ & $95 \% \mathrm{Cl}$ \\
\hline None & 424 & 95.7 & 378 & 95.2 & 1.0 & . & 105 & 99.1 & 1.0 & . \\
\hline$\leq 197$ ppm-years & 10 & 2.3 & 7 & 1.8 & 0.9 & $0.3-2.9$ & 1 & 0.9 & 3.1 & $0.4-27.4$ \\
\hline >197 ppm-years & 9 & 2.0 & 12 & 3.0 & 0.5 & $0.2-1.5$ & . & . & . & . \\
\hline
\end{tabular}

a Odds ratio adjusted for age, body mass index, smoking, alcohol intake, and region.

service occupations revealed the only statistically significant elevated odds ratio in comparison with the population reference group (OR 1.6, 95\% CI 1.2-2.4).

\section{Application of the job-exposure matrix}

Using a job-exposure matrix (22), we determined solvent exposure with a probability of more than $50 \%$ for $4.3 \%$ of the cases (19 persons). The corresponding proportion in the population reference group was 4.8\% (19 persons). The odds ratios in comparison with the population referents were 0.9 (95\% CI 0.3-2.9) for low exposure and 0.5 (95\% CI $0.2-1.5)$ for high exposure (table 3). An odds ratio of 3.1 (95\% CI 0.4-27.4) was determined for low exposure in the comparison with the sleeping laboratory reference group.

\section{Discussion}

In our case-referent study, it was not possible to ascertain any etiologic role of solvents in the genesis of obstructive sleep apnea. An increased "risk" for current work in service occupations may be explained by a nonhomogeneous and socially unequal access to diagnostic facilities. This result could have been caused by multiple testing as well, since we tested 23 different occupational groups.

Our results are particularly valid with regard to the question of accumulated solvent exposure to high exposure over $\geq 10$ years in the comparison with the population referents. For this question, power calculations (including sample size and exposure prevalence in the reference group) revealed that the probability to 
detect an odds ratio of 2 was $80 \%$. But we had to keep in mind that our real power was less due to the possibility of nondifferential misclassification with all of the three approaches used. In comparison with the population reference group, the small number of participants in this reference group (59\%) must also be considered problematic. Highly exposed and ill persons possibly refused participation, and this possibility could have led to an overestimation of the actual risk.

In a restrictive sense, we have referred to the low power, in particular for current solvent exposure (power less than $50 \%$ ) and in comparison with the sleeping laboratory reference group (power for high accumulation of solvent exposure $40 \%$ ). These results should be interpreted with care. However, our results correspond with those of a German study that used a biomarker to assess exposure to solvents (20). This study also did not confirm any association between sleep apnea and solvents. Instead, the sleep apnea correlated with alternating shift work. This finding supports the theory that disturbances in the sleep-wake rhythm aggravate sleep apnea. This mechanism may also be the means for interpreting the observations made by Monstad et al (18), who documented the fall in an apnea index among 12 workers after the end of their exposing occupation.

The hypothesis that solvents induce sleep apnea is mainly based on three Scandinavian studies (17-19). In the first study, subjects who had been exposed to solvents were observed in a sleeping laboratory; they suffered from sleep apnea far more frequently than expected. They were recruited by referral to a neurological clinic due to the clinical suspicion of toxic solvent reaction. Therefore, the selection of the patients took place on one hand due to confirmed solvent exposure and, on the other, due to symptoms typical of sleep apnea. The second study also recruited its participants from among persons exposed to solvents, who had been referred to an occupational medicine department in Uppsala, Sweden, before being sent on to the sleep laboratory. The reasons for the first referral to the occupational medicine institution were not explained. In consideration of our findings, a possible explanation could be that the association between solvent exposure and obstructive sleep apnea found by these studies was due to selection bias.

A third study, in which obstructive sleep apnea patients were compared with population referents, the authors determined an increased odds ratio of 1.9 , which was significant on a $90 \%$ level (19). It is not possible to ascertain the extent to which the increased odds ratio was influenced by the referral practices.

It remains possible, nonetheless, that particularly high and prolonged exposure may sometimes cause sleep apnea (16), although causality cannot definitely be derived from case reports.
In conclusion our results did not support the suggestion of an association between exposure to solvents and obstructive sleep apnea. This conclusion applies in equal measures for the evaluation of the exposure-related information provided by the subjects, for the evaluation of the occupational biography, and for the results of the application of a job-exposure matrix.

\section{Acknowledgments}

This study was financially supported by the Hans Böckler Trust. We are very grateful for its support.

We would also like to thank the participating sleeping laboratories under the leadership of Prof Dr Rüdiger Hopf (Sachsenhausen Hospital, Frankfurt/Main) and Dr Peter Kardos (Red Cross Hospital Maingau, Frankfurt/Main).

\section{References}

1. American Thoracic Society. Indications and standards for cardiopulmonary sleep studies. Am Rev Respir Dis 1989;139: 559-68.

2. Young T, Palta M, Dempsey J, Skatrud S, Weber S, Badr S. The occurrence of sleep-disordered breathing among middleaged adults. New Engl J Med 1993;328:1230-5.

3. Working Group on OSA and Hypertension. Obstructive sleep apnea and blood pressure elevation: what is the relationship? Blood Press 1993;2:166-82.

4. Hoffstein V, Chan CK, Slutsky AS. Sleep apnea and systemic hypertension: a causal association review. Am J Med 1991; 91:190-6.

5. Laks L, Lehrhaft B, Grundstein RR, Sullivan CE. Pulmonary hypertension in obstructive sleep apnea. Eur Respir J 1995; 8:537-41.

6. Guilleminault C, Connolly SJ, Winkle RG. Cardiac arrhythmia and conduction disturbances during sleep in 400 patients with sleep apnea syndrome. Am J Cardiol 1983;52:490-4.

7. Wiemannn J, Grötz J, Konermann M, Glados I, Matura R, Mathejka E. Obstruktive Schlafapnoe als Ursache eines koronaren Gefäßspasmus? In: Schäffle ME, Gehlen W, Schäfer T, editors. Schlaf und schlafbezogene autonome Störungen aus interdisziplinärer Sicht. Bochum (Germany): Universitätsverlag Brockmeyer, 1991:343-6.

8. Bradley TD, Rutherford R, Grossmann RF, Lue F, Zamel N, Moldofsky H, et al. Role of daytime hypoxemia in the pathogenesis of right heart failure in the obstructive sleep apnea syndrome. Am Rev Respir Dis 1985;131:835-9.

9. Palomäki H, Partinen M, Erkinjuntti T, Kaste M. Snoring, sleep apnea syndrome, and stroke. Neurology 1992;42(7 suppl 6):75-82.

10. Cassel W, Ploch T, Peter H, von Wichert P. Unfallgefahr von Patienten mit nächtlichen Atmungsstörungen. Pneumologie 1991;45:271-5.

11. Bliwise DL, Bliwise NG, Partinen M, Pursley AM, Dement WC. Sleep apnea and mortality in an aged cohort. Am J 
Public Health 1988;78:544-7.

12. He J, Meir HK, Kryger MD, Zorick FJ, Conway W, Roth T. Mortality and apnea index in obstructive sleep apnea. Chest 1988;94:9-14.

13. White DP, Lombard RM, Cadieux RJ, Zwillich CW. Pharyngeal resistance in normal humans: influence of gender, age, and obesity. J Appl Physiol 1985;58:365-71.

14. Issa FG, Sullivan CE. Alcohol, snoring and sleep apnea. J Neurol Neurosurg Psychiatry 1982;5:353-9.

15. Wise MG, Fisher JG, de la Plata A. Trichlorethane (TCE) and central sleep apnoea: a case study. J Toxicol Environ Health 1983;11:101-4.

16. Muttray A, Randerath W, Rühle KH, Gajsar H, Gerhardt P, Greulich W, et al. Obstruktives Schlafapnoesyndrom durch eine berufliche Lösungsmittelexposition. Dtsch Med Wochenschr 1999;124:279-81.

17. Edling C, Lindberg A, Ulfberg J. Occupational exposure to organic solvents as a cause of sleep apnoea. Br J Ind Med 1993;50:276-9.

18. Monstad P, Mellgreen SI, Sulg JA. The clinical significance of sleep apnoea in workers exposed to organic solvents: implications for the diagnosis of organic solvent encephalopathy. J Neurol 1992;239:195-8.

19. Ulfberg J, Carter N, Talback M, Edling C. Occupational exposure to solvents and sleep disordered breathing. Neuroepidemiology 1997;16:317-26.

20. Flörke B, Hoffarth P, Pohmer A, Lewalter J, Siegmund K, Borsch-Galetke E. Die Häufigkeit eines Schlafapnoesyndroms (SAS) bei Mitarbeitern eines lösungsmittelverarbeitenden Betriebes der chemischen Industrie. In: BorschGaletke E, Struwe F, editors. Psychomentale Belastungen und Beanspruchungen im Wandel von Arbeitswelt und Umwelt. Fulda (Germany): Rindt-Druck, 1997:313-7.

21. Schulz H, editor. Kompendium der Schlafmedizin für Ausbildung, Klinik und Praxis. Deutsche Gesellschaft für Schlafforschung und Schlafmedizin, Landsberg/Lech:ecomed,1997.

22. Kauppinen T, Toikkanen J, Pukkala E. From cross-tabulations to multipurpose information systems: a new job-exposure matrix. Am J Ind Med 1998;33:409-17.

Received for publication: 15 June 2002 